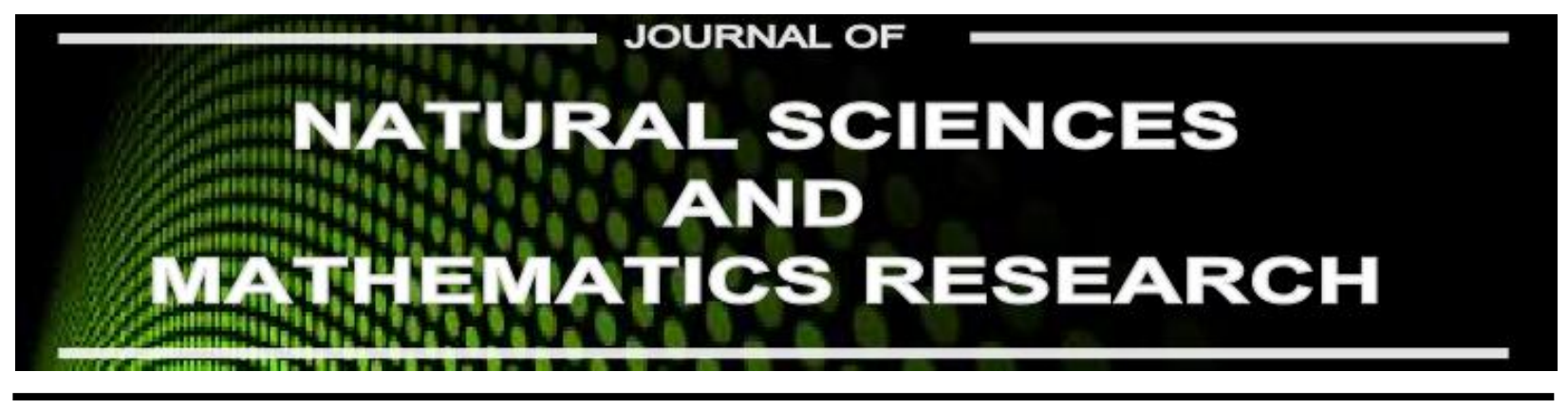

Available online at http://journal.walisongo.ac.id/index.php/jnsmr

\title{
Effect of the Pull and Diameter String of Badminton Racket Based on Coeffisient of Restitution Value
}

\section{Ivan Setia Arianto1, Nuri $^{2}$ and Agus Yulianto ${ }^{3}$}

${ }^{1}$ SMP Islam Al Azhar 29 Semarang, Central Java, Indonesia

${ }^{2}$ SMK Tunas Harapan Pati, Central Java, Indonesia

${ }^{3}$ Physic Department, Faculty of Mathematics and Natural Sciences, Semarang State University, Indonesia

Corresponding author: ivankovic90@hotmail.com Recived: 02 March 2016, Revised: 20 April 2016 Accepted: 25 May 2016.

\begin{abstract}
s
Racket and strings is an important factor in the badminton sport. The aim of this study to analyze the pull and the diameter racket string based on restitution coefficient of shuttlecock. The variation of pull was measured used racket Vinlux Miotex Power 007. Six variation of racket string are $(22,23,24,25,26$, and 27) lbs. The diameter of the strings has kept constant of $0.66 \mathrm{~mm}$. The other variable is the diameter variation of the strings are $(0.62,0.64,0.66,0.68$, and 0.70$) \mathrm{mm}$, respectively and the pull of the strings are kept constant of $24 \mathrm{lbs}$. Based on the result, the increasing of the pull was decreased the COR value, from 0.541 to 0.374 for $22 \mathrm{lbs}$ to $27 \mathrm{lbs}$, respectively. Furthermore, the similar trend for the diameter variation with the pull variation, the COR value was decreases with the increasing of the diameter, from 0.529 to 0.447 for $(0.62$ to 0.70$) \mathrm{mm}$. We can conclude, the increases of the pull and diameter variation was decresed COR value of shuttlecock. (C2016 JNSMR UIN Walisongo. All rights reserved.
\end{abstract}

Key words: String; Racket; Coefisien of restitution.

\section{Introduction}

Badminton is one of the most popular sports in Indonesia. Generally, badminton sport can in Indonesia has become a mainstay for achievement with frequent title. Many world class achievement and the Olympic badminton athletes who achieved so that the name of Indonesia in the international world of sports.
Racket and strings like two sides of a coin that can not be separated. Both are important factors for a game of badminton. Racket superior useless if using strings ugly as easily break off and reflections shuttlecock irregular [1]. Otherwise if you choose a racket carelessly will affect the strength of the strings hold [2]. Racket with greater weight will generate higher ball velocity in the smash than the weight of the racket which is lighter. It was 
due to the acceleration of angular and torque racket bigger than racket heavier [4].

Based on research on the effect of pulling the strings to the velocity of the shuttlecock. By using variations of the pull of the strings 22 lbs, $24 \mathrm{lbs}, 26 \mathrm{lbs}, 28 \mathrm{lbs}, 30 \mathrm{lbs}$ is produced that the higher the pull of the strings, the lower the velocity of the shuttlecock [3, 4]. These results confirmed research that influences pull the strings high will produce a velocity bounce lower than the pull of the strings low $[3,5]$.

Badminton players need to pay attention to elections to determine control racket strings reflection shuttlecock. Shuttlecock reflection related to coefficient of restitution. It greatly affects the game of badminton. The coefficient of restitution (e) is the degree of resilience of a collision that can be expressed through a value [14]. The wider the size of the racket head racket can improve performance by generating a higher coefficient of restitution [6].

The diameter varies racket strings and pull the strings of the racket vary depending on the tastes and needs of players. Installation of the frame racket strings using the Yonex machine to obtain a stable traction. Previous research that the higher the pull of the strings, the lower the reflection shuttlecock [3]. High and low pull the strings depends on the strength of the racket frame. If it is pulled too high, it causes the string is broken or warped so broken racket frame.

This study aimed to analyze the pull and the diameter of the racket strings badminton shuttlecock against the coefficient of restitution. Using variable diameter pull the strings and the strings that are the primary focus of this study. It is hoped this research may help in the selection of players badminton racket strings and pull the strings that correspond to the needs of the game of badminton.

\section{Experiments Procedure}

This study uses two variables. The first variation of the difference pull strings with diameters of the same string to measure the coefficients of restitution shuttlecock. The second variation of the difference in diameter strings with the same string tension to measure the coefficient of restitution. The independent variables in this study and diameter pull strings badminton racquets, dependent variable is shuttlecocks coefficient of restitution.

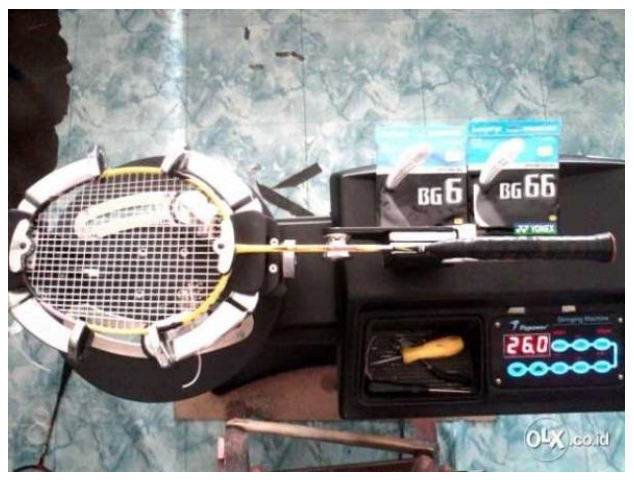

Figure 1. Racket Yonex machine

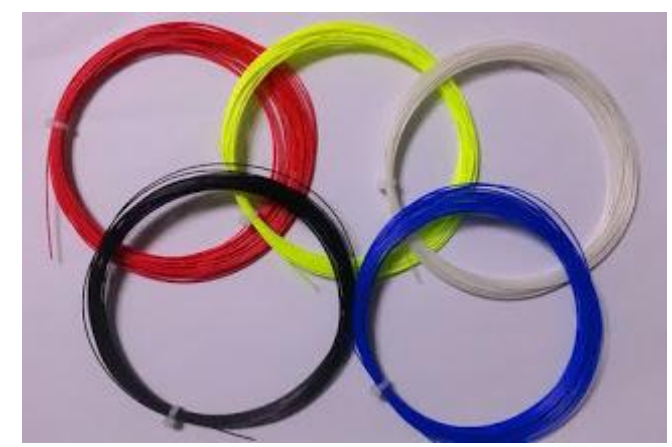

Figure 2. Racket string with difference diameter

Tools (see Figure 1) and materials research (see Figure 2) including 6 badminton racket brands Vinlux Miotech Power 007, 6 brand Yonex badminton rackets, 6 racquet strings with a diameter of $0.62 \mathrm{~mm}$; $0.64 \mathrm{~mm}$; $0.66 \mathrm{~mm} ; 0.68 \mathrm{~mm} ; 0.70 \mathrm{~mm}$, shuttlecock, ruler, balance ohaus, camera iPhone 5S, Yonex racket machine.

Preparation is 6 racket Vinlux Miotech Power 007 disenar Yonex racket using the machine with different pull each $22 \mathrm{lbs}, 23 \mathrm{lbs}$, $24 \mathrm{lbs}, 25 \mathrm{lbs}, 26 \mathrm{lbs}, 27 \mathrm{lbs}$ and diameter strings are made the same, namely $0.66 \mathrm{~mm} .6$ Yonex rackets be assembled using a machine 
with a diameter of $0.62 \mathrm{~mm}$ each; $0.64 \mathrm{~mm}$; $0.66 \mathrm{~mm} ; 0.68 \mathrm{~mm} ; 0.70 \mathrm{~mm}$ and the pull of the strings are made the same, namely $24 \mathrm{lbs}$.

Implementation research is the first variable using a variation of the pull strings to analyze the influence of the shuttlecock coefficient of restitution. Pull strings each 22 lbs, 23 lbs, 24 lbs, 25 lbs, 26 lbs, 27 lbs and diameter strings are made the same, namely $0.66 \mathrm{~mm}$. Four children with different tasks. Racket held with stable under the crossbar mounted vertically to a height measurement of shuttlecock reflection. Shuttlecock dropped at a height of $150 \mathrm{~cm}$, the shuttlecock fall recorded using a camera to determine of high reflectance shuttlecock. High reflection shuttlecock each repeated three times and averaged the results of high-reflection. Recorded in the table for the observation and analysis coefficient of restitution. To measure the shuttlecock coefficient of restitution used Equation 1.

$$
e=\sqrt{\frac{h_{2}}{h_{1}}}
$$

The second variable this research is diameter variation of strings to analyze the influence of the shuttlecock coefficient of restitution. Diameter strings each $0.62 \mathrm{~mm}$; $0.64 \mathrm{~mm} ; 0.66 \mathrm{~mm} ; 0.68 \mathrm{~mm} ; 0.70 \mathrm{~mm}$ and the pull of the strings are made the same, namely $24 \mathrm{lbs}$. Step experiment together with the first variable and its implementation as Figure 3.

\section{Result and Discussion}

Data from the first measurement is a variation of the racket strings pull reflection shuttlecock. Shuttlecock high early before dropped created equal $150 \mathrm{~cm}$. The results of the study indicate variable strings pull on the pull $22 \mathrm{lbs}$ produce COR of 0.541 to pull $27 \mathrm{lbs}$ yield COR of 0.374 . Data showed that the higher the pull of the lower racquet strings reflection shuttlecock shuttlecock so the lower the coefficient of restitution. Influence pull the strings of the shuttlecock coefficient of restitution shown in Figure 4.

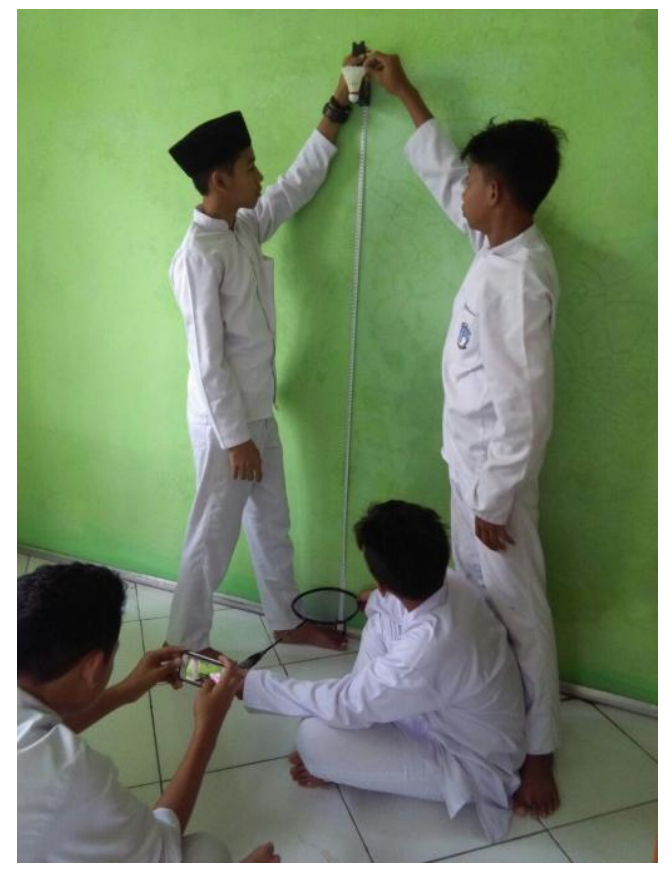

Figure 3. Measuring coeffisient of restitution

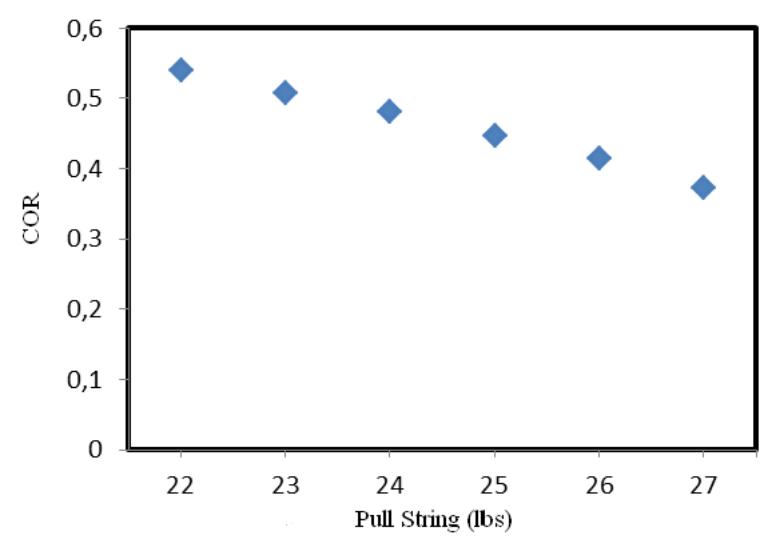

Figure 4. Chart pull string about COR

Selection pull the strings affect the coefficient of restitution shuttlecock. That is because the elasticity of the strings. Pull strings also affects the speed of a shuttlecock. Low traction gives greater reflection speed [4]. Change the speed does not depend on the pull of the strings alone, various pull strings may alter the flexibility of the racket, thereby affecting the speed and there are other factors that cause $[3,4,7]$. Effect of high pull strings 
will yield lower bounce rate than the pull of the strings low [8].

Data from a second measurement is the diameter variation of the reflection shuttlecock racket strings. Shuttlecock made the same early height of $150 \mathrm{~cm}$. In the variable diameter strings indicates the diameter of 0.62 $\mathrm{mm}$ to produce COR 0.529 to $0.70 \mathrm{~mm}$ in diameter to produce COR 0.447. Data showed that the higher diameter racket strings then the lower reflection of shuttlecock so the lower the shuttlecock coefficient of restitution. The influence of the diameter of the strings of the coefficient of restitution shuttlecock can be seen in Figure 5.

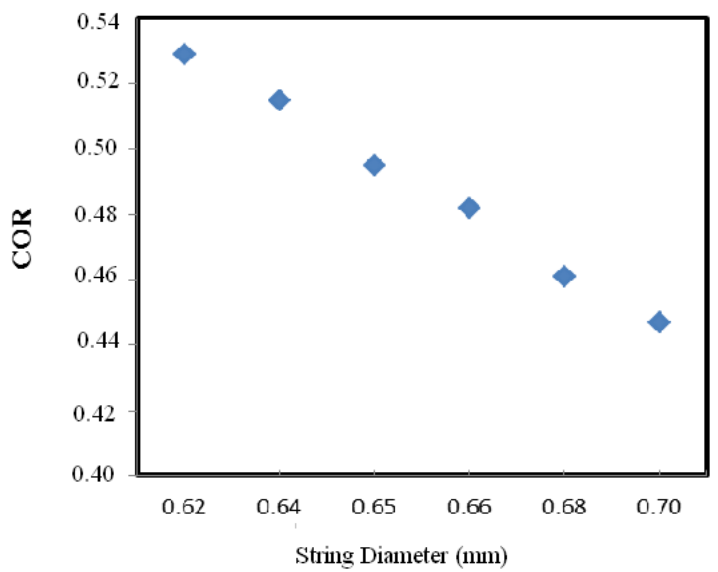

Figure 5.Chart diameter string about COR

Each pull of the strings and the strings diameter has advantages and disadvantages. Large diameter strings are more durable but less elasticity. Diameter thin strings have better elasticity but less endurance and will be more easily broken or dropping $[3,13]$. The higher the pull strings, control and elasticity of shuttlecock gets better and while the pull of the strings that control the shuttlecock low will be more difficult. When pulling high strings, the strings are relatively hard which means shuttlecock and racket face is in contact for a relatively short time. A short contact time means that the strings have relatively little effect when the shuttlecock hit and shuttlecock control more easily [12].

In Figure 6, simulating the effect of pulling the strings of the strength and control of the ball depends on the coefficient of friction on the pull string. The number and duration of use strings elasticity affects the string tension and friction coefficient [9].

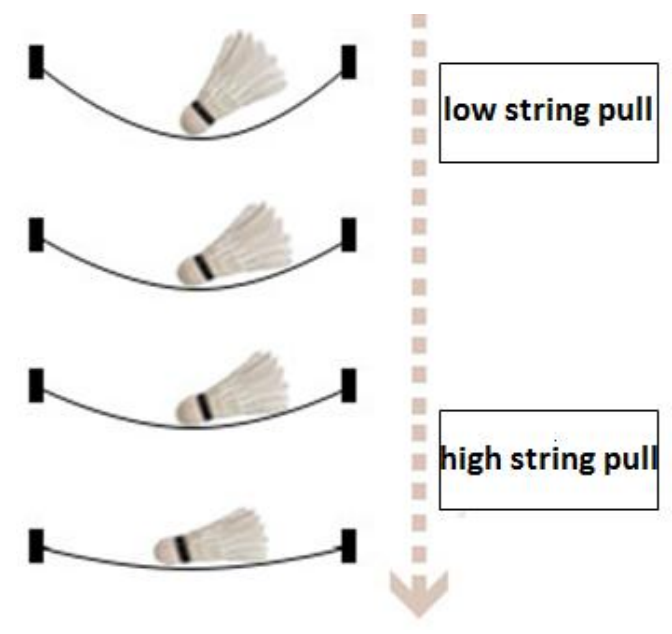

Figure 6. String pull about shuttlecock elastic

The coefficient of restitution is determined shuttlecock and diameter pull the strings. In addition, the determined several factors, including the influence of heavy racket. Racket with greater weight will generate higher ball speed in heavy racket smash than the smaller due to angular acceleration and racket torque larger from racket heavier [2]. These results are corroborated by previous studies that the larger racquet string pull, the smaller the coefficient of restitution of shuttlecock [11]. The wider the size of the racket head racket can improve performance by producing higher COR [6,7]. Location reflection of the ball on the racquet frame also affects the coefficient of restitution [10].

Selection pull strings and diameter considered in need strategy game related factors influence the coefficient of restitution. Comfort when wearing and with the right choice racket strings can then further optimize the game and improve capabilities. Beginners usually still have problems with power punches so it is better to use the pull of the strings is low (22 lbs) as the use of high traction will not provide energy to the punch. 
In contrast to the athletes, their hand muscles have been trained in such a way that it no longer be affected by differences in the pull of which resulted in a strong blow or weak [1]. Athletes prepare on a strong pull in order to further improve the accuracy and control of the blow.

\section{Conclusion}

Study of of the effect of the Pull and diameter of string on the badminton racket has been done. The higher of the string pull causes the lower of coefficient of restitution. Also, the larger of the string diameter will be decreased of coefficient of restitution. Another factor affecting the coefficient of restitution are the racquet frame, heavy racket, and shuttlecock fall position on the racket frame

\section{Acknowledgment}

The author wish to thank Department of Physics, Semarang State Univercity (UNNES) for financial support in this research.

\section{References}

[1] S. Dessianti, Tutorial Olahraga Badminton, Website:

http://www.tutorialolahraga.com/2015/

06/belajar-memahami-tarikan-senar-

raket.html. Accessible on 27 Februari 2016.

[2] H. Chih-Chien, W. Tzu-Lin, W. Jin-eheng, and C. Ming-Ju, The Effect Of Two Different Weighted Badminton Rackets About Velocity And Torque When Outstanding Badminton Players Was Performing Smash Movement. National Chia-Yi University, Chia-Yi, Taiwan. ISBS 2004.

[3] I.S. Arianto, I.S., Aji, M. P., dan Sulhadi. Analisis Tarikan Dan Diameter Senar Raket Badminton Terhadap Pantulan Shuttlecock. Prosiding Smeminar Universitas Negeri Jakarta, Maret 2016.

[4] T. Vanasant, M. Somjarod, and L. Weerawat, The Effect Of String Tension
On Shuttlecock Velocity. Department of Sports Science, Sports Authority of Thailand 2 College of Sports Science and Technology, Mahidol University, Thailand. P02-19 ID108 999-4168, 2013.

[5] R. Bower, and R. Cross, String tension effects on tennis ball rebound speed and accuracy during playing conditions, Journal of Sports Sciences, vol 23(7), pp. 765-71, 2005.

[6] F.A. Nasruddin, F. A. Head Shape Design Analysis of Conceptual Badminton Racket. SpringerBriefs in Computational Mechanics. Sport Innovation and Technology Centre (SITC), Institute Human Centred Engineering (IHCE), Universiti Teknologi Malaysia, Johor, Malaysia. DOI 10.1007/978-3-319-217352_5. 2016.

[7] A. Fakhrizal, and S. Ardiyansyah, Finiteelement study on effect of string tension toward coefficient of restitution of a badminton racket string-bed. Journal of Advanced Material, 845, pp.417-420, 2014.

[8] M. Kwan, S. Andersen, S., and J.Rasmussen, Investigation of high-speed badminton racket kinematics by motion capture. Department of Mechanical and Manufacturing Engineering, Aalborg University, Pontoppidanstraede 101, 9220 Aalborg East, Denmark. Sports Eng 13:5763, 2011.

[9] R. Cross, Flexible beam analysis of the effects of string tension and frame stiffness on racket performance. Physics Department, University of Sydney, Sydney, NSW 2006, Australia. Sports Engineering 3, pp.111-122, 2005.

[10] L. Linlin, Effects of string tension and impact location on tennis playing. Department of Mechanical Engineering, Kyungpook National University, Daegu 702-701, Korea. Journal of Mechanical Science and Technology 23. p.2990 299, 2009.

[11] F.A. Nasruddin, Finite Element Analysis on Badminton Racket Desain Parameters. SpringerBriefs in Computational Mechanics, 2016. 
[12] Victor. Pelatihan Baminton. http://id.victorsport.com/coach.detail_91 81.html. Accessible on 1 March 2016.

[13] Gunawan, T. Kabar Sport, Senar Raket Badminton. Website http://www.kabarsport.com/2015/09/ senarraketbadminton-bulutangkis.html. Accessible on 1 march 2016.

[14] Tipler, P. A. Fisika untuk Sains dan Teknik. by Halliday-Resnick, 1991. 